\title{
Treatment recommendations by clinicians in stage I non-small cell lung cancer: better work-up leads to less discussion
}

\author{
Jo Raskin, Annelies Janssens, Jan P. Van Meerbeeck \\ Department of Thoracic Oncology, Antwerp University Hospital, Edegem, Belgium \\ Correspondence to: Jo Raskin. Department of Thoracic Oncology, Antwerp University Hospital, Wilrijkstraat 10, 2650 Edegem, Belgium. \\ Email: jo.raskin@uza.be. \\ Provenance: This is a Guest Editorial commissioned by Section Editor Cecilia Pompili, MD (Thoracic Surgeon, Clinical Research Fellow, \\ Department of Thoracic Surgery, St. James's University Hospital, Leeds, UK; ESTS Quality of Life and Patient Safety Working Group, UK). \\ Comment on: Hopmans W, Damman OC, Porsius JT, et al. Treatment recommendations by clinicians in stage I non-small cell lung cancer: A study of \\ factors that influence the likelihood of accounting for the patient's preference. Patient Educ Couns 2016;99:1808-13.
}

Submitted Jul 28, 2017. Accepted for publication Aug 04, 2017.

doi: $10.21037 /$ atm.2017.08.17

View this article at: http://dx.doi.org/10.21037/atm.2017.08.17

The current standard of care for stage I non-small cell lung cancer (NSCLC) [small tumours of $<4-5 \mathrm{~cm}$ (depending on the previous or latest TNM classification)] without hilar or mediastinal nodal involvement) is surgical resection (preferably VATS lobectomy), as advocated by all professional guidelines (NCCN; ACCP grade 1B and $\mathrm{ESMO}$ grade $3 \mathrm{~A}$ recommendation), if the patient is medically operable and willing to accept surgical risk (1-3).

For marginally operable patients, guidelines still favour a lesser resection (segmentectomy or wedge resection) over non-surgical intervention (ACCP grade $1 \mathrm{~B}$ recommendation) (2). Surgical series have shown good preservation of pulmonary function after sublobar resection, if not improvement by lung volume reduction in emphysematous lungs (4).

For inoperable patients, the current established treatment is stereotactic ablative radiotherapy (SABR) (1-3). SABR is now challenging surgical resection in operable patients, based on equal 3-year recurrence-free survival and better overall survival, compared to surgery, in $1 \mathrm{RCT}$ (5). These data lead thoracic oncologists-not surprisingly more radiation oncologists-to accept SABR and surgery as equivalent in the treatment of stage I NSCLC, as was the case in $54.8 \%$ of Hopmans' clinicians $(6,7)$.

In case of more than one treatment option, of comparable efficacy and perhaps lesser (albeit of another kind) toxicity, shared decision making, in which the clinician discusses all available options with the patient, to come to a choice supported by both, is advocated, with patient preference being decisive (7). But are perhaps some options more equal than other options (8)?

The only available retrospective data in operable patients originate from the combined results (58 patients!) of two RCTs that closed prematurely due to poor accrual (5). Apparently, clinicians and/or patients, given the choice, are not very keen on risking it with SABR? Retrospective datawith all their limitations-plead in favour of surgery (9) and for clearly operable patients, lobectomy remains the most cost effective option (10).

In addition, no long-term follow-up data are available. Three years are not a lot in a lifetime, and 90-day mortality may be a relevant parameter in surgery-in radiotherapy it is not, as toxicity comes late. Short-term quality of life studies have shown to favour SABR over surgery (5), but the lack of data on long-term effectiveness and toxicity form an important obstacle to its application in young and 'healthy' patients. In addition, surgery in these patients has the advantage of lymph node sampling, possibly identifying patients with a need for adjuvant chemotherapy. Some patients have no preoperative diagnosis; surgery could in these patients identify benign causes of pulmonary lesions and prevent years of unnecessary follow-up after SABR.

Hopmans asked thoracic oncologists to make a recommendation of surgery or SABR to fictitious patients and has shown that SABR is more likely to be recommended by thoracic oncologists in older patients ( $\geq 75$ years), patients 
with poor performance score (WHO-PS 2), patients with $\geq 3$ comorbidities, patients with COPD Gold II and patients who prefer SBRT (6). Except for the latter, are these patients perhaps considered lost for surgery anyway?

Fitness for surgery in Hopmans case vignettesassuming technical resectability is not an issue in these patients-has not been objectified, but is to be derived from severity of a very heterogeneous disease called COPD (Gold II includes both FEV1s of $79 \%$ and $51 \%$ !), as in previous trials with SABR an FEV1 of $<40-50 \%$ was used as a criterion for medical inoperability (11). The same is true, though, for diffusion capacity, not taken into account in the case vignettes, although perhaps even more relevant for both surgery and SABR. Perhaps functional capacity, better reflected by the BODE index (BMI, mMRC dyspnoea scale, 6-minute walk distance, in addition to FEV1) is a better parameter to determine severity of COPD compared to FEV1 alone (12).

Severe cardiovascular disease, diabetes with severe endorgan damage and severe pulmonary hypertension have been used as exclusion criteria for surgery in some trials (11); Hopmans does not specify comorbidities. According to an EORTC Elderly Task Force (Lung Cancer Group)International Society for Geriatric Oncology collaboration chronological age only should not exclude surgical resection in medically operable patients (13).

A thorough preoperative work-up would include cardiopulmonary exercise testing, recommended in all patients with preoperative FEV1 or DLCO $<80 \%$ (14) and evaluation of cardiac risk, which can be estimated through the validated recalibrated thoracic revised cardiac risk index (RCRI) (15).

Results and further treatment should be discussed in a multidisciplinary tumour board, including a pulmonologist with experience in thoracic oncology, thoracic surgeon and radiation oncologist $(2,3)$. We may assume that a significant proportion of Hopmans' patients would be deemed unfit for surgery anyway, thereby closing discussion. Not surprisingly, clinicians' recommendations are influenced by their specialty, belief in the equivalence of surgery and SABR and uncertainty about their advice, but turn out to be only moderately affected by patients' preferences at all (7).

How can they be? Are patients' preferences perhaps not biased, unrealistic or unbalanced? In general, patients are unfamiliar with technique, adverse events and outcomes of thoracic surgery and SABR - let alone interpreting scientific literature; their choices may be heavily influenced by prior appendectomy or radiotherapy for head and neck cancer; fear of surgery and anaesthesia are well-known, radiotherapy is invisible, but is it effective, leaving the tumour in place? Patients more aggressively focusing on survival have been shown to prefer more 'aggressive' surgery (although not superior) in breast cancer (16) and are likely to prefer surgical resection over SABR in lung cancer, while those opting for SABR may rather focus on immediate quality of life.

The verdict is not in yet. Can patients weigh surgery against SABR, when even thoracic oncologists are in doubt?

\section{Acknowledgements}

None.

\section{Footnote}

Conflicts of Interest: The authors have no conflicts of interest to declare.

\section{References}

1. NCCN Clinical Practice Guidelines in Oncology. NonSmall Cell Lung Cancer. Version 7. 2017. Available online: https://www.nccn.org/professionals/physician_gls/pdf/ nscl.pdf, last accessed on July 6, 2017.

2. Howington JA, Blum MG, Chang AC, et al. Treatment of stage I and II non-small cell lung cancer: Diagnosis and management of lung cancer, 3rd ed: American College of Chest Physicians evidence-based clinical practice guidelines. Chest 2013;143:e278S-e313S.

3. Vansteenkiste J, De Ruysscher D, Eberhardt WE, et al. Early and locally advanced non-small-cell lung cancer (NSCLC): ESMO Clinical Practice Guidelines for diagnosis, treatment and follow-up. Ann Oncol 2013;24 Suppl 6:vi89-98.

4. Keenan RJ, Landreneau RJ, Maley RH Jr, et al. Segmental resection spares pulmonary function in patients with stage I lung cancer. Ann Thorac Surg 2004;78:228-33; discussion 228-33.

5. Chang JY, Senan S, Paul MA, et al. Stereotactic ablative radiotherapy versus lobectomy for operable stage I nonsmall-cell lung cancer: a pooled analysis of two randomised trials. Lancet Oncol 2015;16:630-7.

6. Hopmans W, Zwaan L, Senan S, et al. Differences between pulmonologists, thoracic surgeons and radiation oncologists in deciding on the treatment of stage I nonsmall cell lung cancer: A binary choice experiment. Radiother Oncol 2015;115:361-6. 
7. Hopmans W, Damman OC, Porsius JT, et al. Treatment recommendations by clinicians in stage I non-small cell lung cancer: A study of factors that influence the likelihood of accounting for the patient's preference. Patient Educ Couns 2016;99:1808-13.

8. Orwell G. Animal Farm. Secker \& Warburg (London, England), 1945.

9. Deng HY, Wang YC, Ni PZ, et al. Radiotherapy, lobectomy or sublobar resection? A meta-analysis of the choices for treating stage I non-small-cell lung cancer. Eur J Cardiothorac Surg 2017;51:203-10.

10. Shah A, Hahn SM, Stetson RL, et al. Cost-effectiveness of stereotactic body radiation therapy versus surgical resection for stage I non-small cell lung cancer. Cancer 2013;119:3123-32.

11. Crabtree T, Puri V, Timmerman R, et al. Treatment of stage I lung cancer in high-risk and inoperable patients: comparison of prospective clinical trials using stereotactic body radiotherapy (RTOG 0236), sublobar resection (ACOSOG Z4032), and radiofrequency ablation (ACOSOG Z4033). J Thorac Cardiovasc Surg

Cite this article as: Raskin J, Janssens A, Van Meerbeeck JP. Treatment recommendations by clinicians in stage I non-small cell lung cancer: better work-up leads to less discussion. Ann Transl Med 2017;5(21):427. doi: 10.21037/atm.2017.08.17
2013;145:692-9.

12. Celli BR, Cote CG, Marin JM, et al. The body-mass index, airflow obstruction, dyspnea, and exercise capacity index in chronic obstructive pulmonary disease. $\mathrm{N}$ Engl J Med 2004;350:1005-12.

13. Pallis AG, Gridelli C, Wedding U, et al. Management of elderly patients with NSCLC; updated expert's opinion paper: EORTC Elderly Task Force, Lung Cancer Group and International Society for Geriatric Oncology. Ann Oncol 2014;25:1270-83.

14. Brunelli A, Charloux A, Bolliger CT, et al. ERS/ESTS clinical guidelines on fitness for radical therapy in lung cancer patients (surgery and chemo-radiotherapy). Eur Respir J 2009;34:17-41.

15. Brunelli A, Varela G, Salati M, et al. Recalibration of the revised cardiac risk index in lung resection candidates. Ann Thorac Surg 2010;90:199-203.

16. Hamelinck VC, Bastiaannet E, Pieterse AH, et al. Patients' preferences for surgical and adjuvant systemic treatment in early breast cancer: a systematic review. Cancer Treat Rev 2014;40:1005-18. 